ББК 63.4

\author{
Организация конференциии и издание материалов проведень \\ при финансовой поддержке Российского фонда фундаментальных исследований, \\ проект № 19-09-20008
}

Утверждено к печати Ученым советом ИИМК РАН

Редакционная коллегия тома I: В. А. Алёкшин, Л. Б. Кирчо (отв. редакторы),

В. П. Никоноров, В. Я. Стёганцева; В. В. Терёхина

Рецензенты: д. и. н. Л. Б. Вишняцкий, д. и. н. А. А. Выборнов

Программный комитет конференции: академик РАН, д. и. н., проф. М. Б. Пиотровский

(Государственный Эрмитаж, почетный председатель); д. и. н. В. А. Лапшин (ИИМК РАН, председатель); д. и. н. А. В. Головнёв (МАЭ РАН, сопредседатель); д. и. н. В. А. Дергачёв (Высшая антропологическая школа, Молдова, сопредседатель); д. и. н. И. Ф. Попова (ИВР РАН, сопредседатель); академик АН Республики Узбекистан, д. и. н., проф. Э. В. Ртвеладзе (сопредседатель); к. и. н. А. В. Поляков (ИИМК РАН, зам. председателя); к. и. н. В. А. Алёкшин (ИИМК РАН, зам. председателя); д. и. н. Ю. Е. Берёзкин (МАЭ РАН); Dr., Prof. Н. Бороффка (Германский археологический институт, Германия); В. С. Бочкарёв (ИИМК РАН); Dr. Э. Кайзер (Свободный университет Берлина, Германия); к. и. н. М. Т. Кашуба (ИИМК РАН); д. и. н. Л. Б. Кирчо (ИИМК РАН); к. и. н. А. В. Кияшко (Южный федеральный университет); к. и. н. П. Ф. Кузнецов (СГСПУ);

к. и. н. Н. М. Малов (СНИГУ); к. и. н. В. П. Никоноров (ИИМК РАН); Ю. Ю. Пиотровский

(Государственный Эрмитаж); д. и. н., проф. Д. Г. Савинов (Институт истории СПбГУ);

к. и. н. В. Н. Седых (Институт истории СПбГУ); к. и. н. Н. Н. Скакун (ИИМК РАН);

к. и. н. Н. Ф. Соловьёва (ИИМК РАН); к. и. н. А. И. Торгоев (Государственный Эрмитаж); к. и. н. Е. А. Черлёнок (Институт истории СПбГУ)

Организационный комитет конференции: к. и. н. А. В. Поляков (ИИМК РАН, председатель);

к. и. н. В. А. Алёкшин (ИИМК РАН, зам. председателя); В. С. Бочкарёв (ИИМК РАН); ); к. и. н. М. Т. Кашуба (ИИМК РАН); д. и. н. Л. Б. Кирчо (ИИМК РАН);

А. И. Климушина (ИИМК РАН, отв. секретарь); к. и. н. В. П. Никоноров (ИИМК РАН); Ю. Ю. Пиотровский (Государственный Эрмитаж); В. Я. Стёганцева (ИИМК РАН); В. В. Терёхина

(ИИМК РАН, МАЭ РАН, отв. секретарь); к. и. н. Е. С. Ткач (ИИМК РАН); И. Ж. Тутаева (Государственный Эрмитаж); к. и. н. Е. А. Черлёнок (Институт истории СПбГУ)

Древности Восточной Европы, Центральной Азии и Южной Сибири в контексте связей и взаимодействий в евразийском культурном пространстве (новые данные и концепции): Материалы Международной конференции, 18-22 ноября 2019 г., Санкт-Петербург. Т. I. Древняя Центральная Азия в контексте евразийского культурного пространства (новые данные и концепции). К 90-летию со дня рождения патриарха евразийской археологии Вадима Михайловича Массона. - СПб.: ИИМК РАН, Невская Типография, 2019. — 291 с.

ISBN 978-5-907053-34-2

DOI 10.31600/978-5-907053-34-2 


\section{ДРЕВНЕБАКТРИЙСКИЕ ФЛЯГИ}

\section{Т. О. Двуреченская}

Институт археологии РАН, Москва, Россия

DOI: $10.31600 / 978-5-907053-34-2-150-151$

Ключевые слова: Северная Бактрия, керамика, керамические фляги, крепость Узундара.

Керамические фляги являются редким видом посуды в Центральной Азии. Территория Бактрии характеризовалась наличием одной-двух фляг на памятнике (Курганзол - Сверчков 2012; Айханум - Bernard 1973). Однако новейшие исследования в крепости Узундара кардинально изменили ситуацию (Dvurechenskaya 2019: 153-162). Количество керамических фляг на этом памятнике превышает 200 экз., что позволяет детально изучить рассматриваемый вид сосудов.

Фляга является нетривиальным предметом как в наши дни, так и в древности. В древней Бактрии такие сосуды употребляли во время поездок в условиях недостатка воды. Речь идет о передвижении по неизвестной территории, перемещении по пустынной и безводной местности или о преодолении горных дорог. Таким образом, флягу можно определить как атрибут кочевника, торговца или воина.

Вероятность перемещения фляг на большие расстояния осложняет локализацию места происхождения как самой формы фляги, так и конкретных экземпляров этого вида посуды. Существенно затрудняет изучение фляг и малочисленность обнаруженных изделий. Однако при детальном изучении этого вида сосудов появляется возможность определить места появления фляг как формы сосуда и пути их распространения на больших территориях, а также дальнейшее их заимствование и видоизменение.

Фляги, обнаруженные на Узундара, а также происходящие из других памятников греко-бактрийского времени, не являются автохтонными. Известные формы фляг (асимметричная и симметричная) в Бактрию привнесены и до греко-бактрийской экспансии здесь не встречаются. Наиболее древние экземпляры фляг ассиметричной формы найдены под Персепольской платформой и в слое II города Сузы (Воробьёва 1973: 137). Их относят к ахеменидсткому времени. В V в. до н. э. форма распространяется на территорию Приаралья. В Хорезме этот вид сосудов не только перенят местными мастерами, но и существенно переработан и дополнен под местным влиянием, что отражается в появлении ассиметричных фляг с барельефным орнаментом на уплощенной стороне фляги. Широкое распространение эта форма получает и в кочевнических культурах этого региона (Вайнберг, Левина 1993). Фляги часто встречаются в курганных захоронениях, хотя и являются для кочевников предметом импорта.

Таким образом, фляги попали на территорию Бактрии во время греческой экспансии, но, как и в других регионах, они подверглись местному влиянию. Наиболее разительными свойствами бактрийских фляг ассиметричного типа являются: меньшая, чем у известных аналогов с территории Хорезма и Согда, асимметрия их тулова; наличие сложной профилировки перехода выпуклой части фляги в уплощенную; расположение ручек, которое имеет жесткую привязку к верхней трети тулова. Некоторые особенности прослеживаются и в технологии изготовления фляг. Так, бактрийские сосуды в большинстве случаев выполнены на гончарном круге, их горловины встроены в тулово фляги или прикреплены сверху.

Следует заметить, что ранее фляги, в силу их малочисленности, практически не изучали. Однако планомерное и всестороннее рассмотрение собранного на данный момент материала позволит в будущем на примере одной формы проследить распространение и видоизменение данного элемента культуры на обширной территории и в течение длительного времени. 


\section{Литература}

Вайнберг Б. И., Левина Л. М. 1993. Чирикрабатская культура. М. (Низовья Сырдарьи в древности. Вып. 1).

Воробьёва М. Г. 1973. Дингильдже: Усадьба середины 1 тысячелетия до н. э. в древнем Хорезме. М.

Сверчков Л. М. 2012. Тохары. Древние индоевропейцы в Центральной Азии. Ташкент.

Bernard P. 1973. Fouilles d’Aï Khanum (Campagnes 1965, 1966, 1967, 1968). Paris. (Mémoires de la Delegation Archéologique Française en Afghanistan. T. 21).

Dvurechenskaya N. 2019. The Hellenistic Fortress of Uzundara. In: Baumer Ch., Novák M. (eds.). Urban cultures of Central Asia from the Bronze Age to the Karakhanids. Wiesbaden. P. 153-162.

\section{ANCIENT BACTRIAN FLASKS}

Taisiya O. Dvurechenskaya

Institute of Archaeology of the Russian Academy of Sciences, Moscow, Russia

Keywords: Northern Bactria, ceramic flasks, fortress at Uzundara.

In 2014-2018, in the course of excavations of the fortified site at Uzundara, an unprecedented for Northern Bactria number of flasks (more than 200) was uncovered. At present, it has been possible to study this kind of ceramic vessels and to reveal their characteristic peculiarities, both in morphology and manufacturing technology, as well as to find analogies for them.

\section{О НОВЫХ ОТКРЫТИЯХ НА СЕВЕРНОЙ ГРАНИЦЕ БАКТРИИ}

\section{О. В. Бельш}

Институт археологии РАН, Москва, Россия

DOI: 10.31600/978-5-907053-34-2-151-153

Ключевые слова: Северная Бактрия, граница, Бактрийский отряд, фортификации.

В 2013 г. Бактрийский отряд САЭ ИА РАН ${ }^{1}$ совместно с ТАЭ ИИ АН РУз приступил к стационарным комплексным раскопкам открытой в 1991 г. Э. В. Ртвеладзе крепости Узундара. Памятник расположен в Сурхандарьинской обл. Республики Узбекистан, в районе Байсунских гор, на вершине горы Сусизтаг (Двуреченская, Ртвеладзе 2015: 37). Исследователи отмечали, что крепость Узундара является ключевым звеном в системе пограничных укреплений (Ртвеладзе 1990; Двуреченская 2015). Одним из возможных элементов предполагаемой системы пограничной обороны считалась Дарбандская стена, которая находится в 7 км к северу от крепости.

Первые подтверждения наличия укреплений на горе Сусизтаг, которые были бы системно связаны с крепостью Узундара, были получены в ходе разведок 2016 г., проводимых Бактрийским отрядом. Между ущельем Узундара и ущельем Дари-Об был открыт фортификационный комплекс, состоящий из стены протяженностью в 100 м и башни. ${ }^{2}$

Весной 2018 г. Бактрийским отрядом была выявлена еще одна оборонительная стена, находящаяся в 5 км к югу от крепости Узундара, недалеко от кишлака Сайроб. Стена начинается возле ущелья Иллалик (Илон-дара) и тянется на восток на 2,67 км. В свете новых открытий назрел вопрос о тщательных исследованиях склона горы на предмет наличия

\footnotetext{
${ }^{1}$ Руководитель - канд. ист. наук Н. Д. Двуреченская.

${ }^{2}$ Стена сложена из колотого камня, зафиксированная ширина ее в основании 2 м и высота около $1,5 \mathrm{M}$.
} 